\title{
Are Tourists with Higher Expectation More Sensitive to Service Performance? Evidence from Urban Tourism
}

\begin{abstract}
This study aims to revisit the classic topic of tourist satisfaction formation in the context of urban tourism, and contribute to the dialogue by verifying an expectation-as-moderator paradigm. A model depicting the relationship between expectation, service performance, perceived value, and tourist satisfaction was constructed and tested based on three-year survey data collected from two major sectors of tourism industry in Hong Kong (accommodation and attraction), using Moderated Structural Equation Model. The results reveal that the moderation effect of tourist expectation exists in accommodation sector, but does not exist in attraction sector. The conclusion suggests that tourists with higher expectation towards accommodation service tend to be more sensitive to service performance. Theoretical and practical implications are discussed.
\end{abstract}

\section{KEYWORDS}

Urban Tourism; Tourist Satisfaction; Tourist Expectation; Moderation; Moderated Structural Equation Model 


\section{INTRODUCTION}

Due to its profound effect on destination choice, consumption level and loyalty, tourist satisfaction has been a long-standing and over-researched topic in tourism research, with various efforts devoted to investigating its formation and precedents (e.g. Ahmed, 1991; Chen, Li, \& Song, 2016; McDowall, 2011; Song, van der Veen, Li, \& Chen, 2012; Xu \& Zhang, 2016). Previous satisfaction-based studies in both marketing and tourism literature have been dominated by an expectancy-disconfirmation paradigm (EDP), which maintains that customer satisfaction is the result of contrast between expectation and service performance. As such, expectation affects satisfaction indirectly through disconfirmation with actual service performance, whether it is positive disconfirmation (performance exceeds expectation) or negative disconfirmation (performance exceeds expectation) (Oliver, 1980; Weber, 1997).

Popular as it is, the disconfirmation model has been questioned by recent studies for the presumed antecedent role of expectation (Eusébio \& Vieira, 2013; Koenig-Lewis \& Palmer, 2014; Vargo, Nagao, He, \& Morgan, 2007; Wong \& Dioko, 2013). An increasing number of researchers have expressed their concerns on its applicability in typical continuous service consumptions (such as tourism) featuring aggregated, cumulative customer satisfaction, where the consumer (tourist) can learn from the ongoing travel experience, and their prior expectation can be evolving during the trip (Johnson \& Fornell, 1991; Wong \& Dioko, 2013). As such, the disconfirmation model can lose its (constant) standard of comparison, rendering the causal effect of prior expectation questionable (Wong \& Dioko, 2013). This has been confirmed by many empirical studies that reveal insignificant causal effect of pre-trip expectation (e.g. Boo \& Busser, 2018; Eusébio \& Vieira, 2013; Olshavsky \& Kumar, 2001; Wong \& Dioko, 2013). Moreover, some scholars question the marginal benefits of incorporating expectation as antecedent of satisfaction, as performance alone has already demonstrated strong power in predicting satisfaction (Kanning \& Bergmann, 2009; Tse \& Wilton, 1988). The EDP presumes that the absolute level of perceived 
performance is unimportant, but this is contrary to many previous findings that suggest consumer satisfaction is totally independent of customer expectation (e.g. Eusébio \& Vieira, 2013; Lee, Graefe, \& Burns, 2004).

In order to reconcile these disputes, an expectation-as-moderator paradigm has been proposed as an alternative to the EDP, which suggests that pre-trip expectation is likely to be a contextual variable in the (absolute) performance-based satisfaction framework, and shape/moderate the relationship between satisfaction and its evaluative precedents such as service performance and perceived value (Szymanski \& Henard, 2001; Wong \& Dioko, 2013). This moderating effect has been empirically examined in site-level, special consumption settings such as casinos (Wong \& Dioko, 2013), but it is still unknown whether such effect exists in more complex tourism consumption contexts such as urban tourism. Typically, tourist satisfaction and its formation is much more complex in the urban tourism system, which comprises various sectors including attractions, accommodation, restaurants, shopping, transportation (Saayman, Li, Uysal, \& Song, 2018; Song et al., 2012). These sectors are heterogeneous in service provision, servicescape creation, and each forms a unique part of the whole urban tourism experience. This gives rise to two rarely answered questions: "does expectation moderate tourist satisfaction formation in urban tourism?" and, "does the moderating effect of expectation vary across different urban tourism sectors?"

This study aims to answer the above questions by modeling, testing, and comparing the moderating effect of expectation across two major urban tourism sectors (i.e. attractions and accommodation). Hong Kong was selected as research context, and a hypothesized model was proposed based on information processing theory to capture how tourist expectation moderate the relationships between perceived service performance, perceived value, and satisfaction. This model was then tested using moderated structural equation model, based on a large data set $(\mathrm{N}=3841)$ collected through a three-year-in-sequence survey (2011 to 2013). The moderating effects were further compared between the accommodation sector and the attraction sector. This study is distinguished from previous satisfaction studies in that it firstly 
takes a sector-specific and comparative view, and secondly re-structuralizes the relationship between tourist expectation and satisfaction.

\section{LITERATURE REVIEW}

\subsection{Urban tourism}

Urban tourism refers to multiple tourist activities for which the city is the main destination and place of interest. It is an extremely important, world-wide form of tourism, but has yet received sufficient amount of attention from scholars of either tourism or the city. The term itself still remains imprecisely defined and vaguely demarcated, as it solely locates tourism activities, but does not clearly define that activity (Ashworth \& Page, 2011). Relevant empirical studies are scattered amongst topics that are also common to other forms of tourism, e.g. sustainability, destination image, tourist behavior, and are thus far from forming a systematic structure of understanding (Ashworth \& Page, 2011). As such, urban tourism has been treated mostly as a research context, rather than a knowledge body (e.g. McKercher, Shoval, Park, \& Kahani, 2015; Papadimitriou, Apostolopoulou, \& Kaplanidou, 2015).

Urban tourism is distinguished from other tourism forms by its complexity and multi-faceted nature, which in turn has deeply shaped its tourist behavior pattern (Edwards, Griffin, \& Hayllar, 2008). Tourists are generally attracted and served by a diversity of urban characteristics, and their experience is jointly shaped by all accessible space of cities along with the attractions, including the hotels, restaurants, and public transport (Ashworth \& Page, 2011; Cárdenas-García, Pulido-Fernandez, \& Pulido-Fernández, 2016; Xu \& Zhang, 2016).

The complexity of urban tourism system renders it challenging to create tourist satisfaction, as it is a confluence of various sectors, attributes and functions of a tourism city (Edwards et al., 2008; Karski, 1990). Some scholars assert that the overall satisfaction towards a city destination is formulated based on the sum of satisfactory attitudes towards different tourism sectors (e.g. tourism attractions, accommodations) (Wearing \& Foley, 2017), where the attraction and accommodation sectors demonstrate most profound impact on the overall tourist satisfaction (Van 
Limburg, 1998; Yuan, Deng, Pierskalla, \& King, 2018). Other scholars, however, advocate a sector-specific manner in investigating urban tourist satisfaction, as it could be of more pertinence for improving service quality in the specific sector (Brida, Meleddu, \& Pulina, 2012; Li, Fang, Huang, \& Goh, 2015; Shi, Zhao, \& Chen, 2017; Song et al., 2012). More and more researchers agree that comparative studies amongst different urban tourism sectors are needed, so as to capture the heterogeneity of urban tourism (e.g. Agyeiwaah, Adongo, Dimache, \& Wondirad, 2016). Despite these advocates, such sector-specific, comparative studies are insufficient in extant literature.

\subsection{Perceived performance, perceived value and satisfaction}

In the context of urban tourism, tourist satisfaction refers to the degree to which positive emotions and attitudes are evoked in relation to tourism-related services encountered during a city trip (Rust \& Oliver, 1994). In the classic marketing paradigm, providing customers with services that lead to their satisfaction has commonly been considered a critical factor for success in various service businesses including tourism (Bowen \& Chen, 2001; Pizam \& Ellis, 1999). Therefore, determinants of customer satisfaction have been an over-examined topic in both the marketing and tourism literature, with various explanatory frameworks pervasive in leading journals (Jin, Lee, \& Lee, 2015; Song et al., 2012; Wu, Law, \& Liu, 2018).

Extant studies mostly follow Bagozzi’s (1992) “appraisal-emotional response-coping" framework and approach satisfaction as an emotive response stimulated by a combined appraisal of tourism services at post-trip stage (Alegre \& Cladera, 2009). As such, emphases have been largely put on establishing more concrete relationships among cognitively-oriented service factors and satisfaction (Cronin, Brady, \& Hult 2000; Gallarza \& Saura, 2006). In this regard, Fornell et al.'s (1996) classic performance model suggests that customers' perceived service performance is the main predictor of satisfaction, and its effect is partially mediated by perceived value. This model has been widely confirmed by previous tourism studies (Gallarza, Saura, \& Garcia, 2002; Oh, 1999). 
Perceived performance, in the context of urban tourism, refers to a tourist's cognitive appraisal of the superiority of tourism-related service/product in fulfilling their needs during a city trip (Oliver, 1980; Song et al., 2012). Both the marketing and tourism literatures suggest that perceived performance is one of the strongest predictors (or even the sole determinant) of customer satisfaction (e.g. Churchill \& Surprenant, 1982; Eusébio \& Vieira, 2013; Severt et al., 2007). This direct, positive effect has been established through substantial empirical studies in various tourism sectors including accommodation, retailing, tour operator and casino (Boo \& Busser, 2018; Song et al., 2012; Wong \& Dioko, 2013).

The relationship between service performance and satisfaction can be partially mediated by perceived value of the service (Fornell et al., 1996; Song et al., 2012; Wong \& Dioko, 2013). By definition, perceived value refers to an assessment based on the weighing of what is received (i.e. volume, quality or convenience) and what is given (i.e. money, time or effort), and higher perceived value will be perceived when the former out-weights the latter, resulting in a sense of "good value for money" (Lovelock, 2000; Zeithaml, 1988). It can partially mediate between performance and satisfaction because tourists are concerned not only by the excellence level of the service, but also by the cost they need to pay for this level of service. That is, the effect of performance on satisfaction can be eclipsed if it is not perceived as good value for money. Such mediating effect has been underpinned by sufficient empirical evidences that confirm positive relationships between perceived performance and perceived value (e.g. Gallarza \& Saura, 2006; Sweeney \& Soutar, 2001), and between perceived value and satisfaction (e.g. Jin et al., 2015; Lee, Yoon, \& Lee, 2007; Song et al., 2012), in both tourism and non-tourism contexts.

Notably, the performance model has rarely been examined in urban tourism context, where a vast range of product/service offerings (i.e. shops, events, facilities, infrastructure, and transport) are shared between tourists and local residents (Ashworth \& Page, 2011; Su, Bramwell, \& Whallery, 2018). In such a complex situation, perceived performance of different tourism sub-sectors (i.e. attraction and accommodation) and their corresponding effects on tourist satisfaction deserve a 
deeper understanding. Therefore, it is hypothesized that,

Hypothesis 1: Perceived performance (PER) positively affects tourist satisfaction $(S A T)$.

Hypothesis 2: Perceived performance (PER) positively affects perceived value $(V A L)$.

Hypothesis 3: Perceived value (VAL) positively affects tourist satisfaction (SAT).

\subsection{Expectation and the Expectancy-Disconfirmation Paradigm (EDP)}

In the marketing literature, expectation refers to an individual's beliefs/predictions about how a product or service is likely to perform at some moment in the future (Higgs, Polonsky, \& Hollick, 2005; Santos \& Boote, 2003). It is usually formed at pre-purchase stage (Fornell et al., 1996), based on prior knowledge of the products/services collected through non-experiential channels (i.e. advertising or word-of-mouth) and experiential channels (i.e. past experience).

Marketing and tourism researchers have long examined the role of expectation in satisfaction formation. The most popular explanatory framework is the Expectancy-Disconfirmation Paradigm (EDP), which suggests that expectation formed at pre-trip stage also plays a critical role in shaping post-trip satisfaction, and that satisfaction/dissatisfaction is generated via the positive/negative discrepancy between expectations and perceived performance (Oliver, 1980; Pizam \& Milman, 1993; Xu \& Zhang, 2016). In other words, expectation is an antecedent to tourist satisfaction, and can directly/indirectly (through disconfirmation) affect tourist satisfaction (Swart, George, Cassar \& Sneyd, 2017). This disconfirmation framework has been examined by substantial empirical studies in various service sectors (e.g. Chen et al., 2016; Joo, Park, \& Shin, 2017), including tourism (e.g. Pizam \& Milman, 1993; Saayman et al., 2018; Song et al., 2012;Weber, 1997).

Despite its popularity, the EDP has caused disputes over the antecedent role of expectation (Eusébio \& Vieira, 2013; Koenig-Lewis \& Palmer, 2014; Wong \& Dioko, 2013; Zehrer, Crotts, \& Magnini, 2011). Some researchers are concerned with its applicability in the continuous service consumptions (e.g. tourism) which features 
aggregated and cumulative customer satisfaction (Johnson \& Fornell, 1991; Wong \& Dioko, 2013). It is unlikely that a tourist is unable to learn from the ongoing trip experience, and remains constant expectation over different tourism service encounter episodes. As a result, the disconfirmation model can lose its standard of comparison due to the evolving expectation, and thus its causal effect on satisfaction is questionable (Wong \& Dioko, 2013). Echoing such concern, various empirical studies have revealed that the effect of pre-trip tourist expectation is not as significant as expected (e.g. Boo \& Busser, 2018; Eusébio \& Vieira, 2013; Olshavsky \& Kumar, 2001; Wong \& Dioko, 2013). In the meantime, scholars have doubt on the EDP presumption that the absolute level of perceived performance is unimportant, and question the marginal benefits of incorporating expectation as predictors of satisfaction. This is because the absolute performance model has already demonstrated strong power in predicting satisfaction (Kanning \& Bergmann, 2009; Tse \& Wilton, 1988), and many empirical findings suggest that consumer satisfaction is totally independent of customer expectation (Eusébio \& Vieira, 2013; Lee et al., 2004). As such, researchers purport a relationship between service performance and customer satisfaction without considering the disconfirmation framework (Wong \& Fong, 2010; Wong \& Dioko, 2013).

\subsection{Tourist expectation as a moderator}

It has been suggested that more research is needed in order to understand the role of customer expectations, such that the performance model can be sustained, and complex consumptions (such as tourism) and their customer satisfaction can be accounted (Wong \& Dioko, 2013). The most recent studies suggest that pre-trip expectation is likely to be one of the contextual variables (rather than an indirect predictor) in the classic performance-value-satisfaction model, which moderates the relationship between customer satisfaction and its more established predictors, i.e. perceived performance and perceived value (Chen, Peng, \& Hung, 2015; Szymanski \& Henard, 2001; Wong \& Dioko, 2013). Specifically, customers with higher expectation are more likely to transfer their perceived performance regarding 
products/services into a high level of perceived value, and further into satisfaction (Wong \& Dioko, 2013). That is, tourist expectation can strengthen the relationship between perceived performance, perceived value and satisfaction.

This moderating role of expectation takes root in the Selective Information Processing theory, which suggests that customers tend to minimize cognitive dissonance and psychological conflicts by selectively processing information that is related to their prior expectations (Kiesler, Nisbet, \& Zanna, 1969). This implies that customers' prior expectations will interact with new evidences gained during the service encounter, and thus when forming satisfaction, the objective evidence may be interpreted very differently depending on their prior expectation level (Ha \& Hoch, 1989; Oliver \& Winer, 1987). As such, customers with high expectation are likely to attend more to information regarding service performance (superior or poor), and assign greater weight to (superior or poor) service evidence than those with low prior expectations (Dawar \& Pillutla, 2000). As a result, higher expectation can exaggerate both positive and negative evaluation of the service evidence, and make customers be more sensitive to performance change.

This moderating effect has been empirically found in various settings, such as casinos (Wong \& Dioko, 2013), golf (Hutchinson et al., 2009), and heritage sites (Chen \& Chen, 2010). Despite these evidences, the current understanding of expectation as a moderator can be further developed in two aspects. First, there has been discrepancies in the empirical studies, as some researchers provide evidence that the moderating effect of expectation cannot be supported in certain contexts (e.g. Closon, Leys, \& Hellemans, 2015; Yap \& Sweeney, 2007). Second, extant empirical studies are mostly carried out in site-level, non-tourism context featuring unambiguous purchasing (e.g. casino, golf), but it is still unknown whether such effect exists in more complex tourism consumption contexts such as urban tourism. Therefore, this study hypothesizes that:

Hypothesis 4a: Tourist expectation (EXP) will exaggerate the relationship between the perceived value (VAL) and tourist satisfaction (SAT). 
Hypothesis 4b: Tourist expectation (EXP) will exaggerate the relationship between perceived performance (PER) and tourist satisfaction (SAT).

Hypothesis 4c: Tourist expectation (EXP) will exaggerate the relationship between the perceived performance (PER) and the perceived value (VAL).

The above hypothesized relationships are summarized in Figure 1. Based on the aforementioned reasoning, it is anticipated that in a urban tourism context: 1) perceived service performance will positively, directly affect tourist satisfaction; and 2) positively, indirectly affect tourist satisfaction via perceived value, and; these effects will be strengthened by tourist expectation.

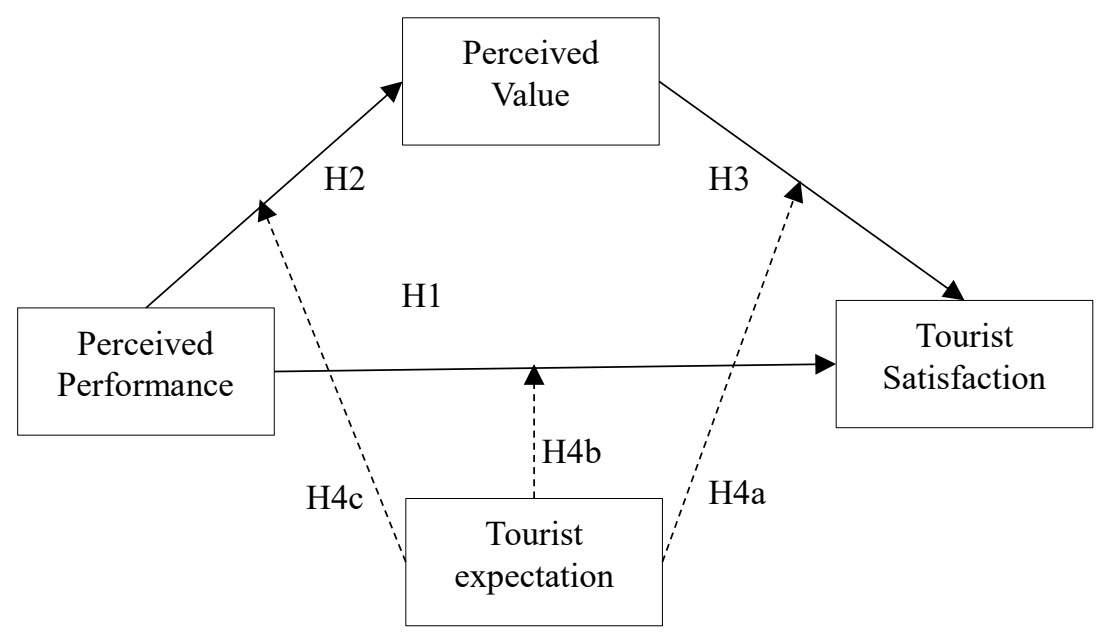

Figure 1. Hypothesized model with moderation effect

\section{METHODOLOGY}

\subsection{Research context: Hong Kong}

Hong Kong has been a world-famous urban destination for decades, and tourism industry has been a critical part of its economy since the late 1980s and early 90s. With the introduction of the Individual Visit Scheme (IVS) in 2003, Hong Kong has seen a sharp increase of domestic tourists from Mainland China, lending to a boom of its tourism industry. More than 60 million tourists are expected to pour into Hong 
Kong in 2018, marking a 3.6 percent uptick year on year. The direct contribution of tourism industry to GDP was HKD 118.7 billion in 2017, making up 4.5\% of the total GDP, and is forecast to rise by $1.5 \%$ from 2018 to 2028 , to HKD 175.0 billion, accounting for $5.2 \%$ of the total GDP in 2028 (World Travel \& Tourism council, 2018).

Hong Kong is renowned for its highly diversified attractions and leading hotel services. Its top ten featured attractions have gained popularity among international tourists for they offer various world-class experiences, including local neighborhoods (Temple Street Night Market, Stanley), modern metropolitan view/night life (The Peak, Tsim-Sha-Tsui Promenade, Golden Bauhinia Square, Lan-Kwai-Fong), shopping (Ladies' Market), theme park (Hong Kong Disneyland, Ocean Park Hong Kong), and cultural heritage (Lantau Island- Ngong Ping). Besides, Hong Kong has one of the largest accommodation sector amongst international cities in the world. Currently it has about 80,000 hotel guest rooms, and the compound annual growth rate (CAGR) of new hotel supply is expected to be 2.4\% between 2018 and 2022 (Yuen, 2018). Both attraction and accommodation sectors are critical to Hong Kong tourism industry.

\subsection{Survey instrument and data}

The data used by this empirical study was generated from the Tourist Satisfaction Index (TSI) survey carried out by the research team. This survey aimed to quantitatively evaluate tourists' expectation (EXP1 to EXP3), perceived service performance (PER1 to PER3), perceived value (VAL1 to VAL2), and satisfaction (SAT1 to SAT3) towards services encountered in the attraction sector and the accommodation sector in Hong Kong. Multi-item measurements are used for all the relevant constructs. All the items measuring the same constructs are supposed to be closely correlated to (but slightly different from) each other, so as to reflect a large proportion of the latent variable variance, and in the meantime to capture the true opinion of the participants from different angles. Scholars generally believe that this measurement approach, in combination with SEM, can reduce the measurement error (by averaging the measurement errors), and thereby increase the accuracy of 
estimation (e.g. Churchill, 1979).

The measurement scales are adapted from previous studies, e.g. Chan et al. (2003), Fornell et al. (1996), Song et al. (2012), and Wong and Dioko (2013), and have been testified by the aforementioned studies in terms of validity and reliability with previous studies. All the measurement items were scored with an 11-point scale ranging from 0 (extremely poor/completely disagree) to 10 (extremely good/completely agree). The survey questionnaire can be found in appendix.

The survey was carried out in different seasons for three years in succession (2011-2013), so as to maintain the representativeness of sample. The target respondents were those tourists who had just finished their trip in Hong Kong, who were surveyed on their left at the port or airport. Well-trained field investigators were recruited to administrate the survey. Due to limited resource and time, this study did not target at all urban tourism sectors. Since attractions and accommodations form the core elements of urban tourism, only data collected from accommodation visitors and attraction visitors was used for the current study. The final dataset includes 4268 samples, with 2136 attraction visitors and 2132 accommodation visitors (without deleting missing data).

\subsection{MSEM and interaction term}

The moderation effects of latent variables are commonly examined using regression analysis with cross terms generated on the summed indicants of independent variables (Ro, 2012), or multi-group structural equation modeling (SEM) which creates subgroups using the summed scores of moderators, and then tests for significant coefficient differences amongst the groups (Myers, Calantone, Page, \& Taylor, 2000). However, both approaches have their weaknesses: product term regression suffers a lack of statistical power for latent variables measured with errors (Aiken \& West, 1991), while multiple group SEM can cause the loss of information and reduction in power for detecting interaction effects (type II error) by artificial grouping (Frazier, Tix, \& Barron, 2004).

This study employs moderated structural equation modeling (MSEM), which 
creates latent interaction variables using products of indicants (Kenny \& Judd, 1984). This is because MSEM has several merits: measurement errors can be controlled, the continuous nature of the moderator can be retained, and the underestimation problem can be relieved (Hoyle \& Smith, 1994). Ping (1995) proposes a simplified MSEM approach with only one indicant for each interaction term, which can avoid redundant variables that are problematic with convergence and infeasible solutions in larger models (Cortina, Chen, \& Dunlap, 2001). This single-indicant MSEM approach has been used by a number of studies such as Conway et al. (2016).

Following the three-step approach proposed by Cortina et al. (2001) and Ping (1995), the single-indicant interaction term was created first according to the following equation:

$$
X Z=\sum_{n=1}^{i} S x_{n} \times \sum_{m=1}^{j} S z_{m}
$$

where $X$ and $Z$ denote the latent independent variable and latent moderator, $i$ and $j$ represent the number of items for $X$ and $Z$, and $S x$ and $S z$ represent standardized values of indicators of $X$ and $Z$.

Next, the path coefficients and the error variance of the interaction term were fixed. The path coefficients from latent interaction $X Z$ to indicator $x z$ were calculated according to the following equation:

$$
\lambda_{X Z}=\sum_{n=1}^{i} \lambda x_{n} \times \sum_{m=1}^{j} \lambda z_{m}
$$

where $\lambda x_{n}$ is the path coefficient from the latent independent variable $X$ to its indicators and $\lambda z_{m}$ is the path coefficient from the latent moderator $Z$ to its indicators.

Finally, the random measurement error for the interaction indicator $x z$ was determined by the following equation: 


$$
\begin{gathered}
\theta \mathrm{xz}=\left(\sum_{n=1}^{i} \lambda \mathrm{x}_{n}\right)^{2} \times \operatorname{Var}(X) \times \sum_{m=1}^{j} \theta z_{m}+\left(\sum_{m=1}^{j} \lambda \mathrm{z}_{m}\right)^{2} \times \operatorname{Var}(Z) \times \sum_{n=1}^{j} \theta x_{n} \\
+\sum_{m=1}^{j} \theta z_{m} \times \sum_{n=1}^{i} \theta x_{n}
\end{gathered}
$$

where $\operatorname{Var}(X)$ and $\operatorname{Var}(Z)$ denote the estimated variance of $X$ and $Y$, respectively, and $\theta x_{n}$ and $\theta z_{m}$ are the random measurement errors of the indicators of $X$ and $Z$.

\section{RESULTS}

\subsection{Descriptive data analysis}

Table 1 and 2 present the result of descriptive data analysis. Notably, the categorization of respondents' origin places is consistent with that of Hong Kong Tourism Board(https://partnernet.hktb.com/australia/en/research_statistics/index.html). Standard deviation values demonstrate moderate degree of variance, and missing data is observed on all items of both sectors. Specifically, data of attraction sector has much less data missing than that of accommodation sector. The missing data was deleted in a listwise way before further analysis. A randomness test of missing data $(\mathrm{t}$ test) was carried out between the subgroup that contains missing data, and the other subgroup without missing data. The result indicated no significant difference $(p>0.1)$ between them, and thus the missing data is random. This finding, coupled with the large sample size (more than 2000 for each sector), leads to the conclusion that the listwise deletion of missing data is not likely to cause systematic biases.

Table 1. Demographic characteristics of the respondents

\begin{tabular}{lllllll}
\hline Attraction sector & & & & $N$ & $\%$ \\
Resident Country & $N$ & $\%$ & Age & 409 & $24.83 \%$ \\
Mainland China & 302 & $18.34 \%$ & $16-25$ & 577 & $35.03 \%$ \\
Taiwan/Macau & 218 & $13.24 \%$ & $26-35$ & 330 & $20.04 \%$ \\
South/South East Asia & 213 & $12.93 \%$ & $36-45$ & 194 & $11.78 \%$ \\
Japan/Korea & 229 & $13.90 \%$ & $46-55$ & 137 & $8.32 \%$ \\
Europe/Africa/Middle East & 247 & $15.00 \%$ & $56+$ &
\end{tabular}




\begin{tabular}{|c|c|c|c|c|c|}
\hline The Americas & 243 & $14.75 \%$ & Education & & \\
\hline South Pacific & 195 & $11.84 \%$ & Primary school/below & 11 & $0.66 \%$ \\
\hline Income (monthly) & & & Secondary/high school & 251 & $15.24 \%$ \\
\hline Less than US $\$ 1,000$ & 145 & $8.80 \%$ & College/university & 1082 & $65.70 \%$ \\
\hline US\$1,000-2,999 & 453 & $27.50 \%$ & Postgraduate & 303 & $18.40 \%$ \\
\hline US\$3,000-4,999 & 346 & $21.01 \%$ & Gender & & \\
\hline US\$5,000-9,999 & 434 & $26.35 \%$ & Female & 783 & $47.54 \%$ \\
\hline US $\$ 10,000$ or more & 269 & $16.33 \%$ & Male & 864 & $52.46 \%$ \\
\hline \multicolumn{6}{|l|}{ Accommodation sector } \\
\hline Resident Country & & & Age & & \\
\hline Mainland China & 265 & $17.25 \%$ & $16-25$ & 341 & $22.20 \%$ \\
\hline Taiwan/Macau & 201 & $13.09 \%$ & $26-35$ & 514 & $33.46 \%$ \\
\hline South/South East Asia & 199 & $12.96 \%$ & $36-45$ & 306 & $19.92 \%$ \\
\hline Japan/Korea & 234 & $15.23 \%$ & $46-55$ & 235 & $15.30 \%$ \\
\hline Europe/Africa/Middle East & 243 & $15.82 \%$ & $56+$ & 140 & $9.12 \%$ \\
\hline The Americas & 205 & $13.35 \%$ & Education & & \\
\hline South Pacific & 189 & $12.30 \%$ & Primary school/below & 20 & $1.31 \%$ \\
\hline Income (monthly) & & & Secondary/high school & 212 & $13.80 \%$ \\
\hline Less than US $\$ 1,000$ & 171 & $11.13 \%$ & College/university & 1006 & $65.49 \%$ \\
\hline US\$1,000-2,999 & 371 & $24.15 \%$ & Postgraduate & 298 & $19.40 \%$ \\
\hline US\$3,000-4,999 & 289 & $18.82 \%$ & Gender & $N$ & $\%$ \\
\hline US\$5,000-9,999 & 424 & $27.6 \%$ & Female & & $50.46 \%$ \\
\hline US $\$ 10,000$ or more & 281 & $18.29 \%$ & Male & & $49.54 \%$ \\
\hline
\end{tabular}

Table 2. Sample distribution

\begin{tabular}{lccllllllll}
\hline Items & \multicolumn{3}{c}{ Accommodation sector } & \multicolumn{3}{l}{ Attraction sector } & \multicolumn{2}{l}{ Total } \\
\multicolumn{1}{l}{} & $N$ & Mean & Std. Dev. & $N$ & Mean & Std. Dev & $N$ & Mean & Std. Dev \\
Tourist expectation & & & & & & & & & \\
EXP1 & 2005 & 7.19 & 1.75 & 2050 & 7.32 & 1.65 & 4055 & 7.26 & 1.71 \\
EXP2 & 1997 & 7.31 & 1.69 & 2041 & 7.38 & 1.62 & 4038 & 7.34 & 1.66 \\
EXP3 & 2000 & 7.28 & 1.72 & 2036 & 7.40 & 1.61 & 4036 & 7.34 & 1.66 \\
Perceived performance & & & & & & & & \\
PER1 & 2005 & 7.39 & 1.90 & 2048 & 7.55 & 1.68 & 4053 & 7.47 & 1.79 \\
PER2 & 1996 & 7.46 & 1.86 & 2047 & 7.56 & 1.65 & 4043 & 7.51 & 1.76 \\
PER3 & 1997 & 7.43 & 1.89 & 2042 & 7.54 & 1.67 & 4039 & 7.49 & 1.78 \\
Perceived value & & & & & & & & & \\
VAL1 & 1995 & 7.26 & 1.99 & 2037 & 7.50 & 1.73 & 4032 & 7.38 & 1.87 \\
VAL2 & 1997 & 7.30 & 2.03 & 2040 & 7.54 & 1.77 & 4037 & 7.42 & 1.91 \\
Tourist satisfaction & & & & & & & & & \\
SAT1 & 1982 & 7.44 & 2.07 & 2043 & 7.83 & 1.73 & 4025 & 7.64 & 1.92 \\
SAT2 & 1983 & 6.75 & 2.14 & 2040 & 7.16 & 1.86 & 4023 & 6.96 & 2.01 \\
SAT3 & 1975 & 7.33 & 1.95 & 2036 & 7.77 & 1.56 & 4011 & 7.55 & 1.78 \\
\hline
\end{tabular}




\subsection{Measurement model}

Confirmatory factor analysis (CFA) was carried out on the aggregated sample $(\mathrm{N}=3841)$ to assess the validity and reliability of the measurement model (See Table 5). The CFA model comprises four constructs (expectation, perceived performance, perceived value, and satisfaction) as well as their measurement items. The results demonstrate good overall fitness $\left(\lambda^{2} / \mathrm{df}=9.994, \mathrm{p}=0.000 ; \mathrm{SRMR}=0.013 ; \mathrm{CFI}=0.993\right.$; RMSEA=0.048). Table 3 shows the results of CFA analysis. All the factor loadings are significant and larger than 0.7. Convergent reliability (CR) values are all larger than 0.7, and AVE values all passed 0.5, except for those of satisfaction (which are 0.681 and 0.416 respectively), implying good convergent validity. For all the constructs (except perceived value), the AVE value is larger than all the squared correlation values with the rest constructs, demonstrating good discriminant validity. Overall, the CFA results show that the measurement mode has good reliability and validity.

Table 3. Result of CFA analysis

\begin{tabular}{lllllllll}
\hline & Loading & Var & CR & AVE & PER & VAL & SAT & EXP \\
PER1 & 0.935 & 0.402 & 0.871 & 0.692 & & 0.592 & 0.540 & 0.554 \\
PER2 & 0.948 & 0.310 & & & & & & \\
PER3 & 0.924 & 0.458 & & & & & & \\
VAL1 & 0.920 & 0.535 & 0.811 & 0.682 & 0.692 & & 0.689 & 0.438 \\
VAL2 & 0.959 & 0.289 & & & & & & \\
SAT1 & 0.859 & 0.960 & 0.681 & 0.416 & 0.396 & 0.389 & & 0.348 \\
SAT2 & 0.802 & 1.443 & & & & & & \\
SAT3 & 0.891 & 0.654 & & & & & & \\
EXP1 & 0.880 & 0.652 & 0.843 & 0.642 & 0.554 & 0.438 & 0.348 & \\
EXP2 & 0.945 & 0.295 & & & & & & \\
EXP3 & 0.915 & 0.449 & & & & & & \\
\hline
\end{tabular}




\subsection{SEM model}

The SEM model fits well with the aggregated sample $\left(\lambda^{2} / \mathrm{df}=4.564, \mathrm{p}=0.000\right.$; $\mathrm{RMR}=0.089 ; \mathrm{CFI}=0.998$; $\mathrm{RMSEA}=0.030)$, the accommodation sample $\left(\lambda^{2} / \mathrm{df}=7.407\right.$, $\mathrm{p}=0.000 ; \mathrm{SRMR}=0.013 ; \mathrm{CFI}=0.993 ; \mathrm{RMSEA}=0.058)$, and the attraction sample $\left(\lambda^{2} / \mathrm{df}=5.564, \quad \mathrm{p}=0.000 ; \quad \mathrm{SRMR}=0.013 ; \quad \mathrm{CFI}=0.990 ; \quad \mathrm{RMSEA}=0.057\right) . \quad$ Figure 2 demonstrates the result of parameter estimation and significance test.

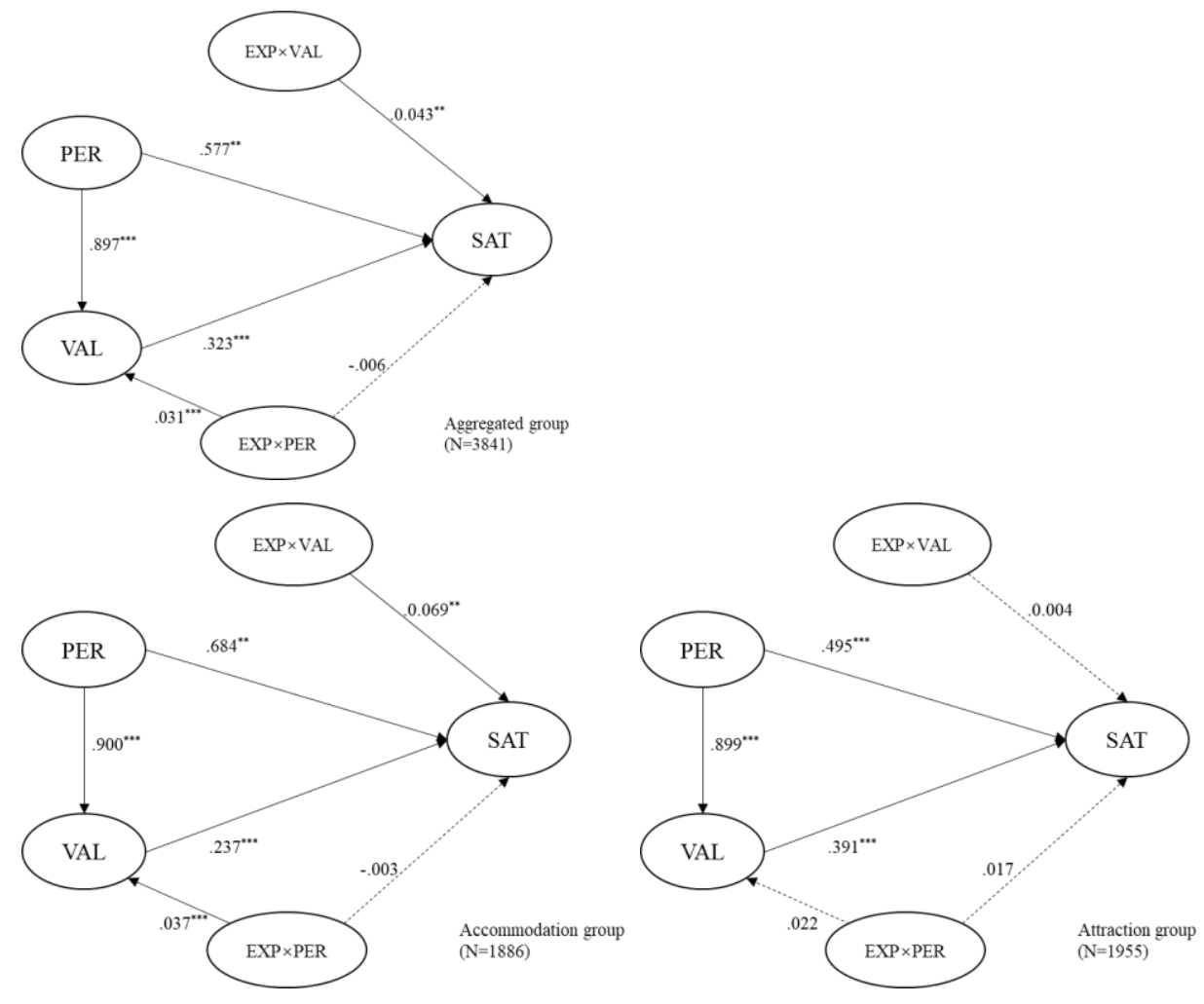

Figure 2. Result of SEM

The effects between performance (PER), perceived value (VAL) and satisfaction (SAT) are examined first. In the aggregated group, perceived service performance directly, positively affect satisfaction $(0.577, p<0.05)$, and indirectly, positively affect satisfaction via perceived value $(0.897 \times 0.323=0.290$; Sobel test statistics $=12.074$, $p<0.01)$. Therefore, Hypotheses 1, 2 and 3 are all supported in the aggregated data set. Similar direct and indirect relationship between perceived performance and satisfaction are also significant in accommodation group (direct effect: $0.684, p<0.05$; 
indirect effect: $0.900 \times 0.237=0.213$, Sobel test statistics $=6.623, \quad p<0.01)$ and attraction group (direct effect: $0.495, p<0.01$; indirect effect: $0.899 \times 0.391=0.352$, Sobel test statistics=8.908, $p<0.01$ ). Thus Hypotheses 1,2 and 3 are also supported in both the accommodation and the attraction sector.

The moderating effects of expectation are represented by two interaction terms, $\mathrm{EXP} \times \mathrm{PER}$ and $\mathrm{EXP} \times \mathrm{VAL}$. In the aggregated group, EXP $\times \mathrm{VAL}$ demonstrates significant, positive effect on satisfaction $(0.043, p<0.05)$, implying that expectation can positively moderate the impact of perceived value on satisfaction. As such, Hypothesis $4 a$ is supported. EXP $\times$ PER has a significant, positive effect on perceived value $(0.031, p<0.01)$, but has no significant effect on satisfaction. Thus expectation positively moderates service performance in terms of its influence on perceived value, but does not moderate its effect on satisfaction. Therefore, Hypothesis $4 c$ is supported, but Hypothesis $4 b$ is not. Hence, the results support the mediated moderation of customer expectations; that is, the moderating effect of customer expectation is mediated through perceived value.

Similar data analysis result can be found in accommodation group, where expectation positively moderate the relationships between perceived value and satisfaction $(0.069, p<0.05)$, and between performance and perceived value $(0.037$, $p<0.01$ ), but has no significant effect on the relationship between performance and satisfaction. Thus in the context of accommodation sector, Hypotheses $4 a$ and $4 c$ are supported, whilst Hypothesis $4 b$ is not supported. In the attraction group, neither $\mathrm{EXP} \times \mathrm{PER}$ or $\mathrm{EXP} \times \mathrm{VAL}$ shows significant effect on perceived value or satisfaction, implying that expectation has no moderating effect in attraction group. Therefore, none of Hypotheses $4 a, 4 b$ and $4 c$ is supported in the attraction sector.

\section{DISCUSSIONS}

The diversified and complex nature of urban tourism warrants the necessity to investigate the heterogeneity amongst different sectors of urban tourism (Neuts \& Nijkamp, 2012; Yuan et al., 2018). The above analyses have generated a series of interesting findings that are worthy of discussion. 
The role of expectation in tourist satisfaction formation was examined by testing a series of hypotheses, and was compared between accommodation sector and attraction sector (Table 6). The performance model (Hypotheses 1, 2, and 3) is supported in all the three groups, and thus it can be concluded that service performance can directly or indirectly (via perceived value) affect tourist satisfaction in the context of urban tourism. Specifically, increased service performance can improve tourist satisfaction either directly or indirectly via enhancing perceived value. This finding is consistent with piles of previous studies in both urban tourism context (Song et al., 2012) and non-urban tourism contexts such as heritage tourism (Chen \& Chen, 2010) and natural tourism (Jin et al., 2015). Similar findings are also generated by studies in many western contexts such as Australia (Kim \& Brown, 2012) and Spain (Gallarza \& Saura, 2006). The partially mediating effect of perceived value also echoes previous studies in that if the service performance is improved with an unacceptable increase in cost, its positive impact on satisfaction can be eclipsed (e.g. Song et al., 2012; Wong \& Dioko, 2013).

Table 6. Result of hypotheses test

\begin{tabular}{llll}
\hline $\begin{array}{l}\text { Hypothesis 1: Perceived performance } \\
\text { positively affects tourist satisfaction. }\end{array}$ & Supported & Supported & Supported \\
$\begin{array}{l}\text { Hypothesis 2: Perceived performance } \\
\text { positively affects perceived value. }\end{array}$ & Supported & Supported & Supported \\
$\begin{array}{l}\text { Hypothesis 3: Perceived value positively } \\
\text { affects tourist satisfaction. }\end{array}$ & Supported & Supported & Supported \\
$\begin{array}{l}\text { Hypothesis } 4 a: \text { Tourist expectation will } \\
\text { exaggerate the relationship between the } \\
\text { perceived value and tourist satisfaction. }\end{array}$ & Supported & Unsupported \\
$\begin{array}{l}\text { Hypothesis } 4 b: \text { Tourist expectation will } \\
\text { exaggerate the relationship between the } \\
\text { perceived performance and tourist }\end{array}$ & & & \\
satisfaction. & & Unsupported \\
$\begin{array}{l}\text { Hypothesis } 4 c: \text { Tourist expectation will } \\
\text { exaggerate the relationship between the } \\
\text { perceived performance and perceived }\end{array}$ & Supported & Supported & Unsupported \\
value. & & & \\
\hline
\end{tabular}


The moderating role tourist expectation (Hypotheses $4 a, 4 b$, and $4 c$ ) is partly supported in the aggregated group: expectation will strengthen the relationships between perceived performance and perceived value, and between perceived value and satisfaction, but has no significant effect on the relationship between perceived performance and satisfaction. This finding echoes and further develops previous studies in that expectation can be one of the contextual variables that moderate the relationship between satisfaction and its determinants (e.g. Chen et al., 2015; Yuan et al., 2018). It can thus be concluded that in the urban tourism context, tourist expectation does exaggerate the effect of service performance on satisfaction, and tourist with higher expectation tend to be more sensitive to performance change. In other words, tourists with high expectation would be easily satisfied given increased service performance and perceived value, and could be easily frustrated if inferior service is provided.

However, tourist expectation can only moderate the indirect effect of service performance (via perceived value), but has no significant influence on the direct performance-satisfaction relationship. Thus it can be further concluded that customers who have high expectation are more likely to transfer their perceived performance into satisfaction solely via a high level of perceived value. This is consistent with Wong and Dioko's (2013) findings in the casino context, and the explanation could be that customers are concerned about both the absolute level of service quality and the price charged (Lovelock, 2000). The positive performance appraisal amplified by the higher expectation through the information selective process, therefore, cannot be transmitted to increased satisfaction without increase the perception of value-for-money.

A further investigation and comparison between accommodation visitors and attraction visitors reveals heterogeneity between these two sectors in terms of moderating expectation, which is significant in accommodation sector but insignificant in attraction sector. This finding echoes previous observations in that the role of expectations in the customer satisfaction model varies across different purchase contexts, depending on the contextual characteristics such as ambiguity 
(Olshavsky \& Kumar, 2001; Wu \& Padgett, 2004; Zeithaml, Berry, \& Parasuraman, 1993). Accommodation service is characterized by being highly standardized, predictable, and unambiguous, and thus tourist expectation is more resistant to contingencies during the consumption process, and thus can have moderating effect. This is consistent with Wong and Dioko (2013) who have found the moderating role of expectation in the formation of tourist satisfaction in the unambiguous casino context. In contrast, tourist attractions features their novelty, and tend to be ambiguous and unpredictable, where tourist has little control on their expectation. While tourists are concerned with the service performance in an accommodation setting, they are more concerned with other experiences at the attraction sites, such as enjoyment and novelty. Such uniqueness of tourist behavior pattern in the attraction can largely weaken the moderating role of expectation.

\section{CONCLUSIONS, IMPLICATIONS, AND LIMITATIONS}

This study aims to contribute to the classic topic of satisfaction formation by revisiting the moderating role of customer expectation in urban tourism context. Drawing on survey data of Hong Kong tourists from 2011 to 2013, this study models and tests the moderating effects of tourist expectation on the conventional performance model, and further compares the effects between two major urban tourism sectors, i.e. the accommodation and the attraction. Such an endeavor is scant in the extant literature, but is necessary in order to verify and generalize the expectation-as-moderator paradigm in urban tourism context.

This study has generated several conclusions. First, tourist satisfaction towards urban tourism service is determined by perceived service performance directly and indirectly (via perceived value), and this performance-based relationship holds true in both accommodation and attraction sectors. Second, tourist expectation can exaggerate the effect of service performance on satisfaction, and tourist with higher expectation tend to be more sensitive to performance change. However, the exaggerating role of expectations is contingent on the mediating effect of the perceived value an urban tourism system can offer, and can be found only in 
unambiguous accommodation sector.

Through these findings, this study can firstly extends the existing literature by providing a richer picture of how tourist satisfaction is shaped in urban tourism. Although there is a large body of marketing literature advocating studies of customer satisfaction, the literature has just begun to understand its formation and heterogeneity in different sectors of urban tourism. By revealing how tourist satisfaction is shaped differently between the accommodation sector and the attraction sector, this study can add to the accumulation of knowledge body.

Meanwhile, this article contributes to tourist satisfaction theory by refreshing the role of expectation. Although the moderating role of expectation has been acknowledged in prior research (Chen et al., 2015; Wong \& Dioko, 2013), limited empirical effort has been undertaken in complex consumption settings such as urban tourism. This research heeds the call from Zeithaml et al. (1993) to understand alternative roles of customer expectations, and lends weight to the notion that expectation may not necessarily function merely as an antecedent or predictor (direct or indirect via disconfirmation) of satisfaction; rather it represents a condition that moderates the effect of more established predictors on it. Thereby, this study reconciles the findings of studies that support the preeminence of perceived performance as a significant direct and indirect (via disconfirmation) precursor of satisfaction (Churchill \& Surprenant, 1982; Kanning \& Bergmann, 2009; Tse \& Wilton, 1988), with those that endorse a more significant role of expectations.

Finally, this analysis is based on a longitudinal data of three years in sequence, which might have higher representativeness. Heterogeneity of different sub-sectors of tourism industry is also taken into consideration, and the differences were identified between accommodation sector and attraction sector in terms of moderation effect of tourist expectation. These endeavors are rarely found in previous literature.

As far as the practical implications are considered, the findings of the current study allude to the importance of monitoring and managing tourist expectation for urban destination management organizations (DMOs). As a destination becomes more outstanding and famous, and as the tourists have higher expectation, the DMOs faces 
more challenges because the tourists will be more critical and more sensitive to service performance. Therefore, rather than simply lowering customer expectations and delivering better-than-expected service and value in the hope of delighting customers, as is suggested by EDP, service providers should communicate clearly the benefits of their service value propositions and strive to fulfill these propositions. This is especially true when the destination is reputational with high market expectation. Creating unambiguous expectations is particularly prudent in marketing to tourists, as it helps to reduce risk aversion. In the meantime, the DMO should be very careful not to over-advertise its service and create overly high expectation that it is unable to fulfill. They should clearly and honestly inform consumers about its service level, because many of the customers are first-time visitors.

This study also has limitations. Although attraction and accommodation are the two most representative sectors of tourism industry, there are also other sectors in tourism department, e.g. F\&B, entertainment, retailing, transportation. Future study may expand the scope of data and take one step further to investigate the effect of tourist expectation in sectors other than accommodation and attraction. Meanwhile, three-year data is indeed far from enough for longitudinal research to capture the dynamic of Hong Kong tourist expectation over time. More time-series data are needed in order to further strengthen the conclusion drawn from the longitudinal comparison. Moreover, the hypothesized relationships could vary depending on the personal characteristics of the tourist. The effects of personal attributes is missing from the current model. Although this may not distort the findings of this study, future studies are encouraged to incorporate the personal attributes into the satisfaction model, so as to gain more comprehensive explanation of tourist satisfaction formation. Lastly, the sample used could be slightly biased towards the younger generations, as over $55 \%$ of them are 26 to 45 years old. This is because visitors during this age is actually the main force for modern tourism, and Hong Kong is very popular amongst young tourists. 


\section{REFERENCES}

Agyeiwaah E., Adongo R., Dimache A. and Wondirad A., Make a customer, not a sale: Tourist satisfaction in Hong Kong, Tourism Management 57, 2016, 68-79.

Ahmed Z.U., The influence of the components of a state's tourist image on product positioning strategy, Tourism Management 12 (4), 1991, 331-340.

Aiken L.S. and West S.G., Multiple regression: Testing and interpreting interactions, 1991, Sage ; Thousand Oaks, CA.

Alegre J. and Cladera M., Analysing the effect of satisfaction and previous visits on tourist intentions to return, European Journal of Marketing 43 (5/6), 2009, 670685.

Ashworth G. and Page S.J., Urban tourism research: Recent progress and current paradoxes, Tourism Management 32 (1), 2011, 1-15.

Bagozzi R.P., The self-regulation of attitudes, intentions, and behavior, Social Psychology Quarterly 55 (2), 1992, 178-204.

Boo S. and Busser J.A., Tourists' hotel event experience and satisfaction: An integrative approach, Journal of Travel \& Tourism Marketing 35 (7), 2018, 895908.

Bowen J.T. and Chen S.L., The relationship between customer loyalty and customer satisfaction, International Journal of Contemporary Hospitality Management 13 (5), 2001, 213-217.

Brida J.G., Meleddu M. and Pulina M., Understanding urban tourism attractiveness: The case of the Archaeological Ötzi Museum in Bolzano, Journal of Travel Research 51 (6), 2012, 730-741.

Cárdenas-García P.J., Pulido-Fernández J.I. and Pulido-Fernández M.D.L.C., The influence of tourist satisfaction on tourism expenditure in emerging urban cultural destinations, Journal of Travel \& Tourism Marketing 33 (4), 2016, 497-512.

Chan L.K., Hui Y.V., Lo H.P., Tse S.K., Tso G.K. and Wu M.L., Consumer satisfaction index: New practice and findings, European Journal of Marketing 37 (5/6), 2003, 872-909. 
Chen C.F. and Chen F.S., Experience quality, perceived value, satisfaction and behavioral intentions for heritage tourists, Tourism Management 31 (1), 2010, 2935.

Chen J.L., Li G. and Song H., Managing tourist satisfaction: An index approach, In: Uysal M., Schwartz Z. and Sirakaya-Turk E., (Eds.), Management science in hospitality and tourism: Theory, practice, and applications, 2016, Apple Academic Press; Palm Bay, FL, 328-342.

Chen A., Peng N. and Hung K.P., The effects of luxury restaurant environments on diners' emotions and loyalty: Incorporating diner expectations into an extended Mehrabian-Russell model, International Journal of Contemporary Hospitality Management 27 (2), 2015, 236-260.

Churchill G.A., Jr., A paradigm for developing better measures of marketing constructs, Journal of Marketing Research 16 (1), 1979, 64-73.

Churchill G.A., Jr. and Surprenant C., An investigation into the determinants of customer satisfaction, Journal of Marketing Research 1982, 491-504.

Closon C., Leys C. and Hellemans C., Perceptions of corporate social responsibility, organizational commitment and job satisfaction, Management Research: The Journal of the Iberoamerican Academy of Management 13 (1), 2015, 31-54.

Conway E., Fu N., Monks K., Alfes K. and Bailey C., Demands or resources? The relationship between HR practices, employee engagement, and emotional exhaustion within a hybrid model of employment relations, Human Resource Management 55 (5), 2016, 901-917.

Cortina J.M., Chen G. and Dunlap W.P., Testing interaction effects in LISREL: Examination and illustration of available procedures, Organizational Research Methods 4 (4), 2001, 324-360.

Cronin J.J., Jr., Brady M.K. and Hult G.T.M., Assessing the effects of quality, value, and customer satisfaction on consumer behavioral intentions in service environments, Journal of Retailing 76 (2), 2000, 193-218.

Dawar N. and Pillutla M.M., Impact of product-harm crises on brand equity: The moderating role of consumer expectations, Journal of Marketing Research 37 (2), 
$2000,215-226$.

Edwards D., Griffin T. and Hayllar B., Urban tourism research: Developing an agenda, Annals of Tourism Research 35 (4), 2008, 1032-1052.

Eusébio C. and Vieira A.L., Destination attributes' evaluation, satisfaction and behavioural intentions: A structural modelling approach, International Journal of Tourism Research 15 (1), 2013, 66-80.

Fornell C., Johnson M.D., Anderson E.W., Cha J. and Bryant B.E., The American customer satisfaction index: Nature, purpose, and findings, Journal of Marketing 1996, 7-18.

Frazier P.A., Tix A.P. and Barron K.E., Testing moderator and mediator effects in counseling psychology research, Journal of Counseling Psychology 51 (1), 2004, $115-134$.

Gallarza M.G. and Saura I.G., Value dimensions, perceived value, satisfaction and loyalty: An investigation of university students' travel behaviour, Tourism Management 27 (3), 2006, 437-452.

Gallarza M.G., Saura I.G. and García H.C., Destination image: Towards a conceptual framework, Annals of Tourism Research 29 (1), 2002, 56-78.

Ha Y.W. and Hoch S.J., Ambiguity, processing strategy, and advertising-evidence interactions, Journal of Consumer Research 16 (3), 1989, 354-360.

Higgs B., Polonsky M.J. and Hollick M., Measuring expectations: Forecast vs. ideal expectations. Does it really matter?, Journal of Retailing and Consumer Services 12 (1), 2005, 49-64.

Hoyle R.H. and Smith G.T., Formulating clinical research hypotheses as structural equation models: A conceptual overview, Journal of Consulting and Clinical Psychology 62 (3), 1994, 429-440.

Hutchinson J., Lai F. and Wang Y., Understanding the relationships of quality, value, equity, satisfaction, and behavioral intentions among golf travelers, Tourism Management 30 (2), 2009, 298-308.

Jin N., Lee S. and Lee H., The effect of experience quality on perceived value, satisfaction, image and behavioral intention of water park patrons: New versus 
repeat visitors, International Journal of Tourism Research 17 (1), 2015, 82-95.

Johnson M.D. and Fornell C., A framework for comparing customer satisfaction across individuals and product categories, Journal of Economic Psychology 12, 1991, 267-286.

Joo Y.J., Park S. and Shin E.K., Students' expectation, satisfaction, and continuance intention to use digital textbooks, Computers in Human Behavior 69, 2017, 83-90.

Kanning U.P. and Bergmann N., Predictors of customer satisfaction: Testing the classical paradigms, Managing Service Quality: International Journal 19 (4), 2009, $377-390$.

Karski A., Urban tourism: A key to urban regeneration, The Planner 1990, 15-17, April_6.

Kenny D.A. and Judd C.M., Estimating the nonlinear and interactive effects of latent variables, Psychological Bulletin 96 (1), 1984, 201-210.

Kiesler C.A., Nisbett R.E. and Zanna M.P., On inferring one's beliefs from one's behavior, Journal of Personality and Social Psychology 11 (4), 1969, 321.

Kim A.K. and Brown G., Understanding the relationships between perceived travel experiences, overall satisfaction, and destination loyalty, Anatolia 23 (3), 2012, $328-347$.

Koenig-Lewis N. and Palmer A., The effects of anticipatory emotions on service satisfaction and behavioral intention, Journal of Services Marketing 28 (6), 2014, $437-451$.

Lee J., Graefe A.R. and Burns R.C., Service quality, satisfaction, and behavioral intention among forest visitors, Journal of Travel \& Tourism Marketing 17 (1), 2004, 73-82.

Lee C., Yoon Y. and Lee S., Investigating the relationships among perceived value, satisfaction, and recommendations: The case of the Korean DMZ, Tourism Management 28 (1), 2007, 204-214.

Li M., Fang L., Huang X. and Goh C., A spatial-temporal analysis of accommodations in urban tourism destination, International Journal of Hospitality Management 45, 2015, 34-43. 
Lovelock C.H., Services marketing, 4th ed., 2000, Prentice Hall International; Englewood Cliffs, NJ.

McDowall S., The festival in my hometown: The relationships among performance quality, satisfaction, and behavioral intentions, International Journal of Hospitality \& Tourism Administration 12 (4), 2011, 269-288.

McKercher B., Shoval N., Park E. and Kahani A., The 'limited' impact of weather on tourist behavior in an urban destination, Journal of Travel Research 54 (4), 2015, $442-455$.

Myers M.B., Calantone R.J., Page T.J., Jr. and Taylor C.R., An application of multiple-group causal models in assessing cross-cultural measurement equivalence, Journal of International Marketing 8 (4), 2000, 108-121.

Neuts B. and Nijkamp P., Tourist crowding perception and acceptability in cities: An applied modelling study on Bruges, Annals of Tourism Research 39 (4), 2012, $2133-2153$.

Oh H., Service quality, customer satisfaction, and customer value: A holistic perspective, International Journal of Hospitality Management 18 (1), 1999, 67-82.

Oliver R.L., A cognitive model of the antecedents and consequences of satisfaction decisions, Journal of Marketing Research 1980, 460-469.

Oliver R.L. and Winer R.S., A framework for the formation and structure of consumer expectations: Review and propositions, Journal of Economic Psychology 8 (4), 1987, 469-499.

Olshavsky R.W. and Kumar A., Revealing the actual roles of expectations in consumer satisfaction with experience and credence goods, Journal of Consumer Satisfaction, Dissatisfaction and Complaining Behavior 14, 2001, 60-73.

Papadimitriou D., Apostolopoulou A. and Kaplanidou K., Destination personality, affective image, and behavioral intentions in domestic urban tourism, Journal of Travel Research 54 (3), 2015, 302-315.

Ping R.A., Jr., A parsimonious estimating technique for interaction and quadratic latent variables, Journal of Marketing Research 32 (3), 1995, 336-347.

Pizam A. and Ellis T., Customer satisfaction and its measurement in hospitality 
enterprises, International Journal of Contemporary Hospitality Management 11 (7), 1999, 326-339.

Pizam A. and Milman A., Predicting satisfaction among first time visitors to a destination by using the expectancy disconfirmation theory, International Journal of Hospitality Management 12 (2), 1993, 197-209.

Ro H., Moderator and mediator effects in hospitality research, International Journal of Hospitality Management 31 (3), 2012, 952-961.

Rust R.T. and Oliver R.W., The death of advertising, Journal of Advertising 23 (4), $1994,71-77$.

Saayman M., Li G., Uysal M. and Song H., Tourist satisfaction and subjective wellbeing: An index approach, International Journal of Tourism Research 20 (3), 2018, $388-399$.

Santos J. and Boote J., A theoretical exploration and model of consumer expectations, post-purchase affective states and affective behaviour, Journal of Consumer Behaviour: International Research and Review 3 (2), 2003, 142-156.

Severt D., Wang Y., Chen P.J. and Breiter D., Examining the motivation, perceived performance, and behavioral intentions of convention attendees: Evidence from a regional conference, Tourism Management 28 (2), 2007, 399-408.

Shi B., Zhao J. and Chen P.J., Exploring urban tourism crowding in Shanghai via crowdsourcing geospatial data, Current Issues in Tourism 20 (11), 2017, 11861209.

Song H., van der Veen R., Li G. and Chen J.L., The Hong Kong tourist satisfaction index, Annals of Tourism Research 39 (1), 2012, 459-479.

Su R., Bramwell B. and Whallery P.A., Cultural political economy and urban heritage tourism, Annals of Tourism Research 68, 2018, 30-40.

Swart K., George R., Cassar J. and Sneyd C., The 2014 FIFA World Cup ${ }^{\text {TM}}$ : Tourists' satisfaction levels and likelihood of repeat visitation to Rio de Janeiro, Journal of Destination Marketing \& Management 8, 2017, 102-113.

Sweeney J.C. and Soutar G.N., Consumer perceived value: The development of a multiple item scale, Journal of Retailing 77 (2), 2001, 203-220. 
Szymanski D.M. and Henard D.H., Customer satisfaction: A meta-analysis of the empirical evidence, Journal of the Academy of Marketing Science 29 (1), 2001, $16-35$.

Tse D.K. and Wilton P.C., Models of consumer satisfaction formation: An extension, Journal of Marketing Research 25 (2), 1988, 204-212.

Van Limburg B., City marketing: A multi-attribute approach, Tourism Management 19 (5), 1998, 475-477.

Vargo S.L., Nagao K., He Y. and Morgan F.W., Satisfiers, dissatisfiers, criticals, and neutrals: A review of their relative effects on customer (dis) satisfaction, Academy of Marketing Science Review 11 (2), 2007, 1-22.

Wearing S.L. and Foley C., Understanding the tourist experience of cities, Annals of Tourism Research 65, 2017, 97-107.

Weber K., The assessment of tourist satisfaction using the expectancy disconfirmation theory: A study of the German travel market in Australia, Pacific Tourism Review $1(1), 1997,35-45$.

Wong I.A. and Dioko L.D.A., Understanding the mediated moderating role of customer expectations in the customer satisfaction model: The case of casinos, Tourism Management 36, 2013, 188-199.

Wong I.A. and Fong V.H., Examining casino service quality in the Asian Las Vegas: An alternative approach, Journal of Hospitality Marketing \& Management 19 (8), $2010,842-865$.

Wu J., Law R. and Liu J., Co-creating value with customers: A study of mobile hotel bookings in China, International Journal of Contemporary Hospitality Management 30 (4), 2018, 2056-2074.

Wu J. and Padgett D., A direct comparative framework of customer satisfaction: An application to internet search engines, Journal of Interactive Marketing 18 (2), 2004, 32-50.

$\mathrm{Xu}$ Z. and Zhang J., Antecedents and consequences of place attachment: A comparison of Chinese and Western urban tourists in Hangzhou, China, Journal of Destination Marketing \& Management 5 (2), 2016, 86-96. 
Yap K.B. and Sweeney J.C., Zone-of-tolerance moderates the service quality-outcome relationship, Journal of Services Marketing 21 (2), 2007, 137-148.

Yuan J., Deng J., Pierskalla C. and King B., Urban tourism attributes and overall satisfaction: An asymmetric impact-performance analysis, Urban Forestry and Urban Greening 30, 2018, 169-181.

Yuen S., Hong Kong's hotel market enjoys highest revenue growth in Asia, Retrieved 18.12.06.

from https://www.marketing-interactive.com/hong-kongs-hotel-market-enjoys-highest-r evenue-growth-in-asia/, 2018.

Zehrer A., Crotts J.C. and Magnini V.P., The perceived usefulness of blog postings: An extension of the expectancy-disconfirmation paradigm, Tourism Management 32 (1), 2011, 106-113.

Zeithaml V.A., Consumer perceptions of price, quality, and value: A means-end model and synthesis of evidence, Journal of Marketing 1988, 2-22.

Zeithaml V.A., Berry L.L. and Parasuraman A., The nature and determinants of customer expectations of service, Journal of the Academy of Marketing Science 21 (1), 1993, 1-12. 


\section{APPENDIX 1. Survey questionnaire}

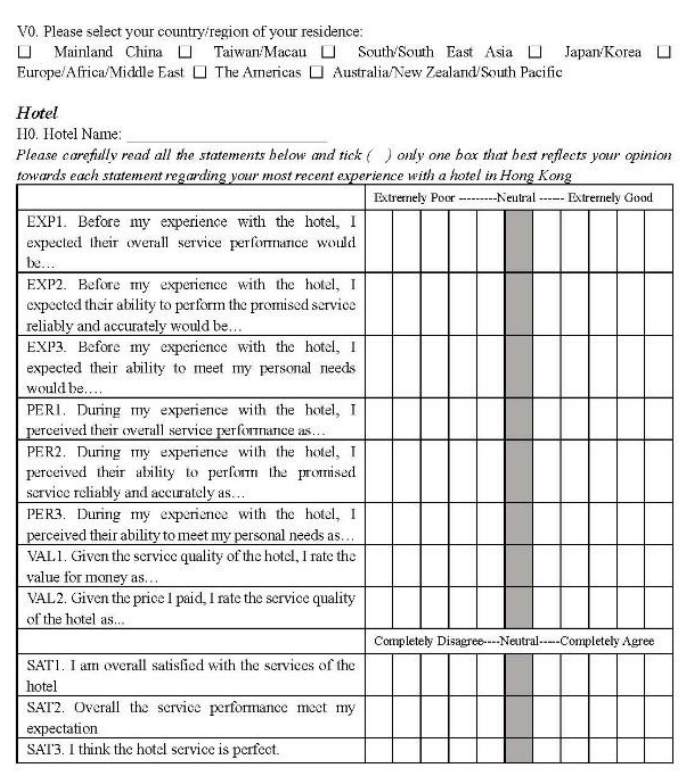

Tourist Attraction (Paid)

The

A0. $\square$ Disney $\square$ Ocean Park $\square$ Victoria Peak $\square$ Ngong Ping $360 \square$ Other (please specify)

Please carefully read all the statements below cand tick () only one box that best reflects your opinion towards ench statement regarding your most recent experience with the attraction in Hong Kong.

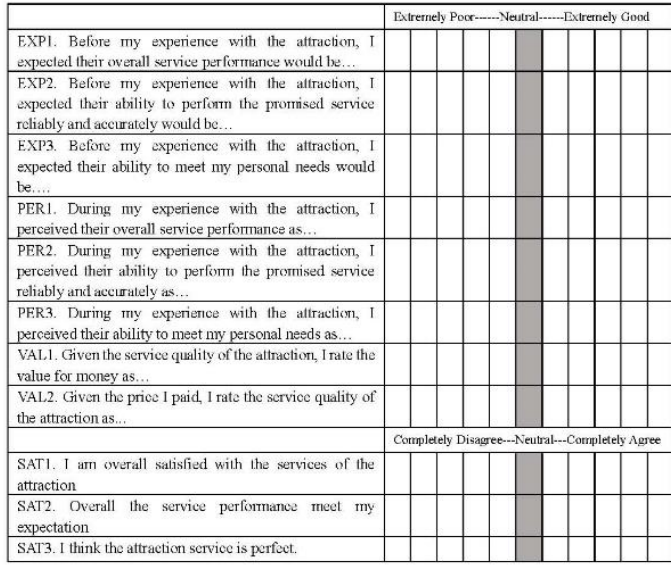

Visitor Profile

Please checks (; only one box in fivon of the appropriate answer that applies to you

V1. Gender.

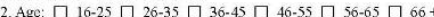

. Education: $\square$ No formal edueation $\square$ Primary/elementary school $\square$ Secondary/high school $\square$ Collegentiniversity $\square$ Pestgraduate

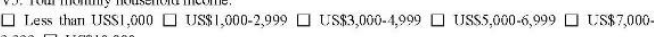
$9,999 \square$ uss 10,000 or more 